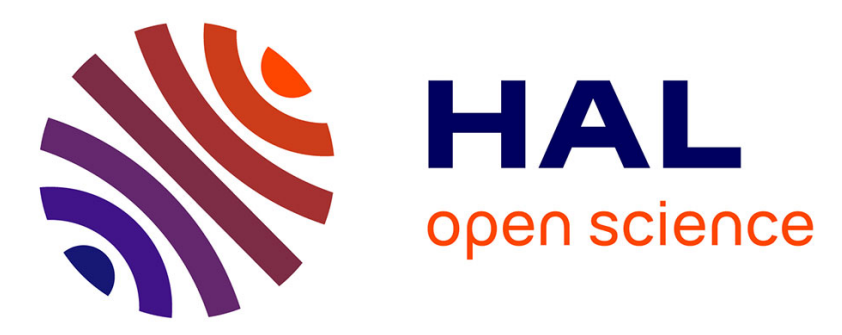

\title{
ELISA detection of hazelnut proteins: effect of protein glycation in the presence or absence of wheat proteins
} Tatiana Cucu, Céline Platteau, Isabel Taverniers, Bart Devreese, Marc de Loose, Bruno de Meulenaer

\section{- To cite this version:}

Tatiana Cucu, Céline Platteau, Isabel Taverniers, Bart Devreese, Marc de Loose, et al.. ELISA detection of hazelnut proteins: effect of protein glycation in the presence or absence of wheat proteins. Food Additives and Contaminants, 2010, 28 (1), pp.1. 10.1080/19440049.2010.535026 . hal-00654490

\author{
HAL Id: hal-00654490 \\ https://hal.science/hal-00654490
}

Submitted on 22 Dec 2011

HAL is a multi-disciplinary open access archive for the deposit and dissemination of scientific research documents, whether they are published or not. The documents may come from teaching and research institutions in France or abroad, or from public or private research centers.
L'archive ouverte pluridisciplinaire HAL, est destinée au dépôt et à la diffusion de documents scientifiques de niveau recherche, publiés ou non, émanant des établissements d'enseignement et de recherche français ou étrangers, des laboratoires publics ou privés. 


\section{ELISA detection of hazelnut proteins: effect of protein glycation in the presence or absence of wheat proteins}

\begin{tabular}{|c|c|}
\hline Journal: & Food Additives and Contaminants \\
\hline Manuscript ID: & TFAC-2010-275.R1 \\
\hline Manuscript Type: & Original Research Paper \\
\hline $\begin{array}{r}\text { Date Submitted by the } \\
\text { Author: }\end{array}$ & $14-O c t-2010$ \\
\hline Complete List of Authors: & $\begin{array}{l}\text { Cucu, Tatiana; Ghent University, Department of Food Safety and } \\
\text { Food Quality; Ghent University, Department for Biochemistry and } \\
\text { Microbiology } \\
\text { Platteau, Céline; Flemish Government, Institute for Agricultural and } \\
\text { Fisheries Research, Technology and Food Science Unit } \\
\text { Taverniers, Isabel; Flemish Government, Institute for Agricultural } \\
\text { and Fisheries Research, Technology and Food Science Unit } \\
\text { Devreese, Bart; Ghent University, Department of Biochemistry and } \\
\text { Microbiology } \\
\text { De Loose, Marc; Flemish Government, Institute for Agricultural and } \\
\text { Fisheries Research, Technology and Food Science Unit } \\
\text { De Meulenaer, Bruno; Ghent University, Department of Food Safety } \\
\text { and Food Quality }\end{array}$ \\
\hline Methods/Techniques: & Immunoassays, Screening - ELISA \\
\hline Additives/Contaminants: & Allergens \\
\hline Food Types: & Plants \\
\hline
\end{tabular}




\section{ELISA detection of hazelnut proteins: effect of}

\section{protein glycation in the presence or absence of}

\section{wheat proteins}

Tatiana Cucu $^{\text {a,c,\$ }}$, Céline Platteau ${ }^{\text {a,b, } \$ \text {, Isabel Taverniers }}{ }^{\text {b }}$, Bart Devreese ${ }^{\text {c }}$, Marc De Loose $^{b, d}$, Bruno De Meulenaer ${ }^{a^{*}}$

${ }^{a}$ Department of Food Safety and Food Quality, Research Group Food Chemistry and Human Nutrition, Ghent University, Ghent, Belgium

${ }^{\mathrm{b}}$ Flemish Government, Institute for Agricultural and Fisheries Research (ILVO), Technology and Food Science Unit, Merelbeke, Belgium

${ }^{c}$ Department of Biochemistry and Microbiology, Laboratory for Protein Biochemistry and Biomolecular Engineering, Ghent University, Ghent Belgium

${ }^{\mathrm{d}}$ Department of Molecular Genetics, Ghent University, Ghent, Belgium

\$ These authors contributed equally

* Corresponding author: Ghent University, Coupure Links 653, B-9000, Belgium. Tel.:+329264 61 66; fax: + 32926462 15. E-mail address: Bruno.DeMeulenaer@ UGent.be 


\section{Abstract}

Hazelnuts are widely used in the food industry, especially confectionary foods. Nevertheless, these nuts contain several allergenic proteins which may be unexpectedly

4 present as contaminants in various foods and may pose a serious threat to allergic consumers. The enzyme-linked immunosorbent assay (ELISA) is the preferred method to assess the level

6 of hazelnut protein contamination. It is commonly used both by the food industry and enforcement agencies. Several ELISA kits are commercially available. However, protein

8 detectability by ELISA may be affected by severe changes that proteins undergo during processing. The aim of this study was therefore to investigate the impact of processing on the

10 ability to detect hazelnut protein by four commercial ELISA kits. Hazelnut proteins in the presence or absence of soluble wheat proteins were modified with glucose via the Maillard

12 reaction. Changes in hazelnut proteins, such as the formation of protein bound carbonyls, losses of reactive lysine residues and free amino groups, and severe aggregation dramatically

14 affected the hazelnut protein detection by the commercial kits. The observed impact was highly dependent on the type of ELISA kit used.

16

Keywords: Hazelnut allergy, ELISA, detectability, Maillard reaction, reactive lysine, protein 18 bound carbonyls, aggregation 


\section{Introduction}

Food allergy is an abnormal immunological response due to sensitization to a food component. Food allergies have become an important health problem, especially in 22 industrialized countries, where they have been estimated to affect about $2 \%$ of the adult population and up to $8 \%$ of children (Monaci et al., 2006). Together with the hen's egg, cow's

24 milk, fish, crustacean, peanut, soybean and wheat, tree nuts are typically associated with severe allergic reactions. Among the latter, hazelnut (Corylus avellana) allergy is becoming

26 more important because of its increased incidence, which is related to the homology between the major birch pollen allergen Bet $v 1$ and the allergens from hazelnut (Hansen et al., 2003).

28 As a consequence, hazelnut allergies are predominantly secondary allergies. Hazelnut allergy can cause severe reactions and occurs mostly throughout the European population with a 30 prevalence between 0.1 and 0.5\% (Birmingham et al., 2005; deGroot et al., 1996). Moreover, numerous cases of hazelnut contamination of foods have been reported (Kiening et al., 2005;

32 Pele Maria et al., 2007).

Given that the only effective treatment for hazelnut or other food allergies is the 34 complete avoidance of the food containing the allergen, this represents an important food safety problem. Directive 2007/68/EC specifies a list of 14 allergic raw materials which must

36 be labeled when present in the food as an ingredient (European Parliament and Council Directive 2007/68/EC, 2007). However, due to the growing complexity of food formulation 38 and food processing, food may be unintentionally contaminated via allergen-containing ingredients or carry-over during processing. For this reason, accurate screening of the raw

40 materials and the end products is essential. However, no "gold standard methods" exists for detection of food allergens. At present, the enzyme-linked immunosorbent assay (ELISA) is most frequently used in routine food analysis because it is relatively cheap, easy to perform and highly sensitive. ELISA methods are based on specific molecular interactions between 
44 the antibodies used in the assay and the analyte, in this case proteins. During food processing, however, proteins undergo changes such as aggregation, polymerization, degradation and random unfolding. Moreover, food proteins often interact with other food components during processing and can lead to additional modifications at the protein level. Therefore, the antibody-protein interaction during the analytical procedure might be affected and potentially lead to erroneous assay results (De Meulenaer et al., 2005).

Hazelnuts are frequently used in food products containing significant amounts of sugar (e.g. cookies, chocolate, breakfast cereals and, nut spreads). During thermal treatment and 52 storage, hazelnut proteins might be modified by the Maillard reaction, which occurs between a reducing sugar and amino groups in proteins. The products formed as a result of Maillard 54 reaction are significant in foods because they are responsible for flavor and color (Brands and van Boekel, 2001). Abundant evidence exists for how thermal processing together with 56 Maillard reaction can greatly influence the $\operatorname{IgE}$ binding activity of food allergens (Gruber et al., 2004; Gruber et al., 2005; Nakamura et al., 2005; Nakamura et al., 2008). In contrast, little 58 information is available on how thermal processing and the Maillard reaction influence the performance of commercially available ELISA kits for allergen detection. Such kits are often 60 used in the food industry and official food agency laboratories to detect and quantify hidden allergens in food. Recently, Scaravelli et al. demonstrated that thermal treatment of cookies 62 spiked with peanut caused a decline in the detection of Ara h1 and Ara h2 by two commercial ELISA kits (Scaravelli et al., 2009).

The aim of this study was to investigate whether the Maillard reaction in the presence or absence of soluble wheat proteins affects the detectability of hazelnut proteins in solution.

66 This was done in $1 \%$ buffered protein solutions incubated with $6 \%$ glucose at $70^{\circ} \mathrm{C}$ for up to $48 \mathrm{~h}$. A model system with soluble wheat proteins was chosen, given that wheat is one of the bulk ingredients in cookies and breakfast cereals. First, the impact of the Maillard reaction on 
1

2

4

5

6

7

8

9

10

11

12

13

14

15

16

17

18

19

20

21

22

23

24

25

26

27

28

29

30

31

32

33

34

35

36

37

38

39

40

41

42

43

44

45

46

47

48

49

50

51

52

53

54

55

56

57

58

59

60

the hazelnut proteins was assessed by evaluating the losses of reactive lysine residues and of

70 free amino groups, generation of protein bound carbonyls and changes in the SDS-PAGE pattern. Additionally, the influence on the hazelnut protein detectability was assessed by

72 analyzing the modified protein solutions by four commercially available ELISA kits: Veratox ${ }^{\circledR}$ for Hazelnut, Ridascreen ${ }^{\circledR}$ FAST Hazelnut, Hazelnut Residue and BioKits 74 Hazelnut Assay were used for this purpose. 


\section{Materials and methods}

\section{Reagents and standards}

Soluble wheat proteins "Meripro 711" were kindly provided by Syral Belgium N.V.

78 (Aalst, Belgium). Chemicals and standards of analytical grade were purchased from SigmaAldrich (Bornem, Belgium), VWR (Leuven, Belgium) and Acros Organics (Geel, Belgium).

80 Analytical grade solvents and technical grade hexane were obtained from Chem-Lab (Zedelgem, Belgium). Gel and standards for SDS-PAGE came from Bio-Rad (Nazareth,

Belgium) while the Krypton protein stain was provided by Thermo Scientific (Aalst, Belgium). The commercial ELISA kits used were Veratox ${ }^{\circledR}$ for hazelnut (Neogen, Lansing, 4 USA), Ridascreen® FAST Hazelnut (R-Biopharm, Darmstadt, Germany), BioKits Hazelnut Assay (Tepnel, Flintshire, UK) and Hazelnut Residue (ELISA Systems, Queensland, 86 Australia).

\section{Hazelnut protein extraction}

Hazelnuts from nine different brands were purchased in Belgian local supermarkets; eight brands were virgin and one was roasted. A mixture of the hazelnuts was made by taking equal amounts of each kind. Hazelnuts were frozen with liquid nitrogen and ground in a twostep process, first with a blender (Moulinex, France) then with an Ultra Turrax t25 (IKA, 92 Wilmington, US).

The in-house prepared hazelnut protein extracts were obtained following Yeung and

94 Collin's protocol (Yeung and Collins, 1996). In summary, $100 \mathrm{~g}$ of ground nuts were defatted four times using $1 \mathrm{~L}$ technical hexane each time. After allowing the solvent to evaporate overnight at ambient temperature, $10 \mathrm{~g}$ of the defatted powder was mixed with $100 \mathrm{~mL}$ of extraction buffer and mixed at $4^{\circ} \mathrm{C}$ over night. Protein extraction buffer consisted of $1 \mathrm{M}$ $98 \mathrm{NaCl}, 1.47 \mathrm{mM} \mathrm{KH}_{2} \mathrm{PO}_{4}, 2.7 \mathrm{mM} \mathrm{KCl}$ and $10 \mathrm{mM} \mathrm{Na} \mathrm{HPO}_{4}$. Sodium azide $0.2 \mathrm{~g} \mathrm{~L}^{-1}$ was 
added to the extraction buffer to avoid microbial growth. Further, a mixture of protease

102 phenylmethylsulfonyl fluoride (PMSF)) was added to the extraction buffer to increase the stability of the protein isolate during extraction and storage (Bjorksten et al., 1980). The

104 protein mixture was further centrifuged for $1 \mathrm{~h}$ at $4^{\circ} \mathrm{C}$ and $20000 \mathrm{~g}$ to separate the lees. Subsequently, the clear supernatant was dialyzed (Spectra/Por 3 membrane tubing, MWCO

$1063.5 \mathrm{kDa}$ ) using the extraction buffer with the protease inhibitors containing only $0.137 \mathrm{M}$ $\mathrm{NaCl}$, for $48 \mathrm{~h}$ at $4{ }^{\circ} \mathrm{C}$ and then filtered through a $0.45 \mu \mathrm{m}$ membrane filter (Puradisc FP 30,

108 Novolab, Belgium). Finally, the protein solution was lyophilized and stored at $-20^{\circ} \mathrm{C}$ until further use. This extract was used as the reference extract.

110 Maillard reaction in the absence of soluble wheat proteins

Hazelnut protein extracts were dialyzed in $0.1 \mathrm{M}$ phosphate buffer $\mathrm{pH} 7.4$ (Spectra/Por

1123 membrane tubing, MWCO $3.5 \mathrm{kDa}$ ) before treatment to remove the nitrogen-containing protease inhibitors. All reaction systems were prepared in the same phosphate buffer $(\mathrm{pH} 7.4)$

114 by mixing $1 \%(\mathrm{w} / \mathrm{v})$ hazelnut proteins with $6 \%(\mathrm{w} / \mathrm{v})$ glucose. The reaction systems in closed falcon tubes were incubated in a water bath at $70^{\circ} \mathrm{C}$ for up to $48 \mathrm{~h}$. A glucose-free reaction

116 system was used as a control. Samples were retrieved from the water bath and placed in an ice bath to stop the reaction at specific times. Further, the modified protein solutions were 118 immediately used for the determination of reactive lysine residues, protein bound carbonyls, free thiol and free amino groups. Aliquots for SDS-PAGE were frozen at $-20^{\circ} \mathrm{C}$ until further use. 


\section{Maillard reaction in the presence of soluble wheat proteins}

122

Two types of glucose-containing model systems were prepared. One model system was obtained by mixing $0.25 \%(\mathrm{w} / \mathrm{v})$ of hazelnut proteins with $0.75 \%(\mathrm{w} / \mathrm{v})$ of wheat proteins and

$1246 \%(\mathrm{w} / \mathrm{v})$ of glucose. Another model system was obtained by mixing $0.5 \%(\mathrm{w} / \mathrm{v})$ hazelnut proteins with $0.5 \%(\mathrm{w} / \mathrm{v})$ wheat proteins and $6 \%(\mathrm{w} / \mathrm{v})$ glucose. Respective model systems 126 without glucose were prepared as control. These systems were then treated similarly as the model systems containing no soluble wheat proteins.

\section{Assessment of the Maillard reaction}

\section{Determination of the protein bound carbonyls}

130 Protein bound carbonyls were measured after converting them to the corresponding 2, 4- dinitrophenylhydrazones. Briefly, $300 \mu \mathrm{L}$ protein solution was incubated with $400 \mu \mathrm{L} 2.4$ 132 dinitrophenylhydrazine (DNPH) $10 \mathrm{mM}$ in $2 \mathrm{M} \mathrm{HCl}$. Further, the proteins were precipitated with $10 \%$ trichloroacetic acid (final concentration) and thoroughly washed with $1 \mathrm{~mL}$ 134 ethanol/ethyl acetate (1:1) after derivatization; hence any unreacted DNPH or DNPH bound to any other components than protein, was removed. Finally, the pellet was redissolved in $6 \mathrm{M}$

136 urea and absorbance was measured at $370 \mathrm{~nm}$ using a Bio-Rad Benchmark Plus microplate spectrophotometer (Nazareth, Belgium). The carbonyl content was calculated using a molar 138 absorption coefficient of $22000 \mathrm{M}^{-1} \mathrm{~cm}^{-1}$ and the results were expressed in $\mathrm{nmol}$ bound carbonyls/mg protein.

140 Loss of reactive lysine residues

The loss of reactive lysine residues was monitored using derivatization with ortho142 phthaldialdehyde (OPA) in the presence of 2-mercaptoethanol yielding a fluorescent product with a maximum excitation wavelength of $340 \mathrm{~nm}$ and emission of $450 \mathrm{~nm}$ (Ferrer et al., 144 2003) and measured by a Spectramax Gemini XPS fluorimeter from Molecular Devices 
148 Free amino groups determination

The modification of free amino groups was determined using derivatization with 2, 4, 6150 trinitrobenzene sulfonic acid (TNBS) as previously described (Fields, 1972). Briefly, $0.5 \mathrm{~mL}$ of protein solution (containing between $0.05-0.25 \mathrm{mg}$ proteins) was incubated with $0.5 \mathrm{~mL}$

152 of $0.1 \mathrm{M}$ tetraborate buffer prepared in $0.1 \mathrm{M} \mathrm{NaOH}$. Next, $20 \mu \mathrm{L}$ of $0.5 \%$ TNBS solution was added to the proteins and the reaction mixture was incubated for exactly 10 minutes at

154 room temperature. To stop the reaction, $2 \mathrm{~mL}$ of stop solution (1.5 mL of $0,1 \mathrm{M} \mathrm{Na} \mathrm{S}_{2} \mathrm{O}_{3}$ with $98.5 \mathrm{~mL}$ of $0.1 \mathrm{M} \mathrm{NaH}_{2} \mathrm{PO}_{4}$ ) were added. The absorbance of the resulting mixture was read at

$156420 \mathrm{~nm}$ using a Cary $50 \mathrm{UV}$-Vis Spectrophotometer from Varian (Sint-Katelijne-Waver, Belgium). The amount of free amino groups was calculated using a molar absorption

158 coefficient of $22000 \mathrm{M}^{-1} \mathrm{~cm}^{-1}$ and results were expressed in nmol free amino groups/mg protein.

160 SDS-polyacrylamide gel electrophoresis (SDS-PAGE)

Protein cross-linking or fragmentation was analyzed by SDS-PAGE under reducing

162 conditions. A 4\% acrylamide stacking gel and a 10\% acrylamide resolving gel were used for protein separation. An aliquot of $10 \mu \mathrm{L}$ sample containing $6 \mu \mathrm{g}$ of protein was added to $10 \mu \mathrm{L}$

164 Laemmli sample buffer containing $\beta$-mercaptoethanol and heated at $95^{\circ} \mathrm{C}$ for 5 min. The samples were further loaded on the gel along with a Precision plus protein unstained 166 molecular weight marker (Bio Rad, Nazareth, Belgium). Krypton fluorescence staining was used to visualize the bands. The gels were read using the Molecular Imager PharosFX Plus 
168 from Bio Rad (Nazareth, Belgium) and the respective molecular weights of the hazelnut proteins were recorded.

\section{Protein determination}

Protein determination was performed by determining the nitrogen content according to

172 the Kjeldahl procedure (AOAC Official Method 981.10, 1981). A factor of 5.41 was used to convert nitrogen to total hazelnut protein, and 6.25 to convert to total protein content for the

174 hazelnut wheat protein mixtures. The non-protein nitrogen (NPN) fraction was determined in the supernatant after a previous protein precipitation with 15\% TCA (final concentration).

\section{ELISA assays}

Samples of the above-described model systems were analyzed using four different

178 commercial ELISA kits: Veratox ${ }^{\circledR}$ for hazelnut (Neogen), Ridascreen ${ }^{\circledR}$ FAST Hazelnut (RBiopharm), BioKits Hazelnut Assay (Tepnel) and Hazelnut Residue (ELISA Systems). The 180 four kits were applied to the different model systems. These model systems included (1) $1 \%$ hazelnut proteins, (2) $1 \%$ hazelnut proteins with $6 \%$ glucose, (3) $0.5 \%$ hazelnut $+0.5 \%$

182 soluble wheat proteins, (4) $0.25 \%$ hazelnut $+0.75 \%$ soluble wheat proteins, (5) $0.5 \%$ hazelnut $+0.5 \%$ soluble wheat proteins and $6 \%$ glucose, (6) $0.25 \%$ hazelnut $+0.75 \%$ soluble

184 wheat proteins and $6 \%$ glucose. Of the different model systems, samples retrieved after 0,24 and $48 \mathrm{~h}$ incubation at $70^{\circ} \mathrm{C}$ were analyzed. The untreated sample ( $=0 \mathrm{~h}$ of thermal treatment $)$

186 of the glucose-free model system (1) containing only hazelnut proteins is referred to as the reference sample. Before the analysis, dilution series were made of the different samples in

188 the extraction buffer or dilution solution of the respective kits. The actual concentrations are the concentrations of hazelnut proteins based on the absolute protein determination using the

190 Kjeldahl procedure and do not include the wheat proteins that were added in some of the model systems. The dilution series of the samples were analyzed in duplicate in the different 
192 kits according to the manufacturers' instructions. Absorbance measurements were made in a microtiter plate reader (Multiskan MCC/340, Titertek, Huntsville, Alabama). Each kit was

194 calibrated using the respective standard protein solutions included in each kit. For fitting the absorbance values to the protein concentration of the standard solutions, a four-parameter196 logistic dose-response curve was used with equation 2.1 below. This equation represents a standard way to express immunoassay data, where $a$ is the maximum dose (protein 198 concentration) of the curve, $b$ is the minimum concentration, $c$ is the $\mathrm{E}_{50}$-value (concentration at half-maximal saturation), $d$ is the slope of the curve and conc is the concentration of the 200 standard or sample (Englebienne, 2000).

$$
\text { Absorbance }=\left[\frac{(b-a)}{\left(1+\frac{\text { conc }}{c}\right) \wedge d}\right]+a
$$

202 For the Ridascreen ${ }^{\circledR}$ FAST Hazelnut data were also fitted according to a cubic spline function as described in the manufacturer's instructions. In case of the Veratox for Hazelnut the kit's 204 procedure recommended fitting the data to log-logit function, which is a linearization of the four-parameter logistic function. For the Hazelnut Residue and the BioKits Hazelnut Assay 206 no suggestion was made with respect to curve fitting. Only the data obtained within the range of the respective standard curves were considered in the results. Outlying data are indicated by

an

asterisk

$(*)$

in

the

charts. 
$210 \quad$ Results

\section{Progress of the Maillard reaction}

212 The interaction of reducing sugars or dicarbonyl compounds derived from sugars may lead to the formation of protein-bound carbonyls (Stadtman and Levine, 2003). Therefore, the 214 amount of protein bound carbonyls was used as an indicator of the Maillard reaction. A timedependent increase of protein bound carbonyls was observed in all model systems used

216 (Figure 1). In the pure hazelnut protein samples, an almost seven-fold increase was observed after incubation for $48 \mathrm{~h}$ in the presence of glucose while incubation in the absence of glucose 218 led to only a slight increase in protein carbonyls (about a three-fold increase). Incubation of hazelnut proteins in the presence of wheat proteins and glucose similarly led to an increase in 220 the measured protein bound carbonyls, but less than the similar model systems in which no wheat proteins were present.

When incubating hazelnut proteins with glucose a gradual decrease of the reactive lysine residues was observed as incubation time increased. This led to a $64 \%$ loss after $48 \mathrm{~h}$ of

224 incubation. (Figure 2). In contrast, incubation in the absence of glucose did not affect the reactive lysine content of the hazelnut protein, even after $48 \mathrm{~h}$ of incubation. The reaction 226 systems containing $0.5 \%$ and $0.75 \%$ wheat proteins contained slightly lower amounts of reactive lysine residues as compared with the model system containing no wheat proteins,

228 which is in line with the lysine deficiency of wheat proteins. Upon incubation, 60 to $70 \%$ losses of reactive lysine residues during the first $24 \mathrm{~h}$ were observed, while further incubation 230 did not further affect the reactive lysine content.

Figure 3 shows the SDS-PAGE pattern of the hazelnut protein incubated with glucose 232 in the presence or absence of soluble wheat proteins. The SDS-PAGE pattern of the native 
240 due to the lower amounts of hazelnut present. Wheat proteins used in the model systems were partially hydrolyzed resulting in a lack of clearly visualized bands.

hazelnut proteins is characterized by the presence of proteins in the molecular weight range of 23410 to $80 \mathrm{kDa}$. The major hazelnut allergens detected were the Bet $v 1$ related Cor $a 1$ and the oleosin Cor a 12, both with a molecular weight of $17 \mathrm{kDa}$; Cor a 9 - a $11 \mathrm{~S}$ globulin with

236 acidic $(35-40 \mathrm{kDa})$ and basic ( 20kDa) subunits, and Cor a 11 which represents a $48 \mathrm{kDa}$ glycoprotein. Further, Cor a 10, a luminal binding protein of $73 \mathrm{kDa}$ was detected along with 238 the profilin Cor a 2 of $14 \mathrm{kDa}$ (Robotham et al., 2009). When soluble wheat proteins were present in the model systems the intensity of the main hazelnut proteins bands became weaker 244 formation occurred, which is manifested by their presence at the boundary of the resolving and stacking gel, as well as in the stacking gel. The high-molecular mass aggregates on top of

246 the gel could not migrate into the stacking gel. They probably have molecular masses larger than $300 \mathrm{kDa}$. Upon addition of the soluble wheat proteins, it was obvious that the formation

248 of these high molecular weight complexes was partially inhibited in a wheat protein concentration dependent manner. Nevertheless, after $48 \mathrm{~h}$ of incubation, smearing and 250 formation of high molecular weight aggregates were still visible.

\section{Detection with commercial ELISA kits}

The concentration of the standards included in three of the four kits tested (Veratox ${ }^{\circledR}$ for hazelnut, Ridascreen ${ }^{\circledR}$ FAST Hazelnut and BioKits Hazelnut Assay) is expressed as a particular amount of hazelnut. However, the samples of the different prepared model systems have a known or actual hazelnut protein concentration. To be able to compare the actual concentration of the samples that were analyzed with the measured concentration derived from the calibration curve obtained with the kit's standards, the concentration of the standards 
258 was converted to the same dimension of that from the model system samples. This was done according to the formula below (3.1), taking into consideration the protein content of the 260 hazelnut standards as indicated in the manual of the kit or, if not indicated, a protein content of $12 \%$ was used (Belser et al., 1999).

262

$$
\text { concentration hazelnut } \mathrm{x} \text { protein content }(\%)=\text { concentration hazelnut protein }
$$

The hazelnut or hazelnut protein concentration of the kit's standards is expressed in 266 parts per million ( $\mathrm{ppm}$ ) which equals $\mathrm{ng}$ analyte/mg food product. However, as the concentration of the hazelnut proteins in the model systems is expressed in $\mathrm{ng} \mathrm{mL}^{-1}$, the 268 concentrations of the kit's standards were converted according to formula 3.2, considering the weight of the sample (mg) extracted by a particular volume of extraction buffer $(\mathrm{mL})$

270 according to the respective manufacturers' instructions.

$$
\text { ppm }=\frac{\text { ng analyte }}{m g \text { food }} \times \frac{\text { weight of extracted sample }(\mathrm{mg})}{\text { volume of extraction buffer used }(\mathrm{ml})}=\frac{\text { ng analyte }}{\text { ml solution }}
$$

For the evaluation of the kits' performance, a dilution series of the hazelnut protein solutions obtained from the six different model systems were applied in the appropriate concentration range of each kit. The obtained absorbance values were converted to a measured hazelnut protein concentration, which was compared with the actual protein 278 concentration presents in each diluted solution (Figure 4).

\section{Veratox for hazelnut}

For the "Veratox ${ }^{\circledR}$ for hazelnut" kit, calibration curves established with the standard hazelnut solutions provided in the kit, were fitted to the four-parameter-logistic function. The 
282 log-logit fit, according to the manufacturer's instructions, is a linearization of the sigmoid shape of the four-parameter logistic function. Consequently, both fittings return the same 284 concentration for a given absorbance value. After conversion of the concentrations according to formulas 3.1 and 3.2 , the standards covered a range from zero to $120 \mathrm{ng} \mathrm{mL}^{-1}$ hazelnut 286 protein. The actual hazelnut protein concentration present in the reference sample and its dilutions was dramatically underestimated - on average by $94 \%$ (Figure 4A). Upon heating 288 the reference sample for $24 \mathrm{~h}$ at $70^{\circ} \mathrm{C}$ without glucose, the discrepancy increased between the actual hazelnut protein concentration present and the protein concentration measured by the 290 kit. Only up to $4 \%$ of the actual hazelnut protein present could be detected (data not shown). When the heat treatment up to $48 \mathrm{~h}$ the detectability decreased down to about $3.3 \%$ on 292 average.

Once soluble wheat proteins $(0.75 \%)$ were added to the reference hazelnut protein 294 sample (0.25\%), an underestimation was again observed. Only $12.6 \%$ of the actual hazelnut protein concentration by the kit. This was only marginally less dramatic compared to the 296 reference protein samples to which no wheat proteins were added. Remarkably, if a lower amount of wheat proteins was present $(0.5 \%$ hazelnut $+0.5 \%$ soluble wheat proteins $)$ even 298 less of the actual hazelnut protein concentration was observed (9.6\% detected, not shown). Upon heating the mixture of hazelnut and soluble wheat protein solutions a further decrease in

300 the measured hazelnut protein concentration was observed, although the decrease was less pronounced compared to the similarly treated samples in the absence of soluble wheat 302 proteins (17\% compared to $45 \%$ loss in signal compared to the native reference sample in the absence and presence of soluble wheat proteins, respectively).

Upon addition of glucose during heating, the discrepancy between the actual and measured hazelnut protein concentration increased dramatically, both in the absence and 
306 presence of soluble wheat proteins ( $2 \%$ or less of the actual hazelnut protein concentration was measured).

308 Ridascreen ${ }^{\circledR}$ FAST Hazelnut

The values obtained for the standards using the "Ridascreen ${ }^{\circledR}$ FAST Hazelnut" kit were 310 fitted to the four-parameter-logistic and a cubic spline function. After conversion according to the formulas given above, the standards ranged from zero up to $90 \mathrm{ng} \mathrm{mL} \mathrm{L}^{-1}$ hazelnut protein. 312 After analysis of a dilution series of the reference hazelnut protein sample with the Ridascreen ${ }^{\circledR}$ FAST Hazelnut only the data for the samples actually containing less than $50 \mathrm{ng}$ $314 \mathrm{~mL}^{-1}$ hazelnut protein could be considered, as the samples with a higher concentration returned absorbance values outside the range of the kits standard curve.

316 The measured concentrations of the reference sample were underestimated by about $17 \%$ using the logistic standard curve, except for the lowest concentration $\left(5 \mathrm{ng} \mathrm{mL}^{-1}\right)$, which 318 was underestimated by $49 \%$ (Figure 4B). With the cubic spline fit the calculated concentrations were about $10 \%$ higher than with the four-parameter logistic function. 320 However, using the former fitting, no calculations could be made for samples with an absorbance value between zero and that of the first standard. Heat-treatment of the reference 322 sample at $70^{\circ} \mathrm{C}$ led to a limited loss in detectability after $48 \mathrm{~h}$ (about $13 \%$ ).

When soluble wheat proteins were added $(0.75 \%)$ to the reference hazelnut protein 324 sample $(0.25 \%)$ the protein concentration was either underestimated by $12 \%\left(40 \mathrm{ng} \mathrm{mL}^{-1}\right)$ or overestimated by $15 \%\left(20 \mathrm{ng} \mathrm{mL}^{-1}\right)$. For the lowest concentration $\left(4 \mathrm{ng} \mathrm{mL}^{-1}\right)$ the obtained 326 signal resulted in a calculated concentration equal to zero. In the presence of a lower amount of soluble wheat proteins $(0.5 \%$ hazelnut protein $+0.5 \%$ soluble wheat proteins $)$ the samples 328 were underestimated by $80 \%$ on average (data not shown). Heating alone of the mixture of hazelnut and soluble wheat proteins, led to a loss in detectability (signal reduced on average 330 by $30 \%$ after $24 \mathrm{~h}$ with an additional loss of $15 \%$ after $48 \mathrm{~h}$ incubation as compared to the 
native samples). This loss in detectability was more pronounced as compared with the

332 similarly treated reference hazelnut protein solution in the absence of wheat proteins (13\% reduction). Addition of glucose during heating led to a greater discrepancy between the actual

334 and measured concentrations. In the presence of wheat proteins the signal further decreased further by about $30 \%$. Interestingly, in the absence of wheat proteins an increased 336 detectability was observed after heating for $48 \mathrm{~h}$.

\section{Hazelnut Residue}

The calibration curves obtained with the standards of the "Hazelnut Residue" kit were fitted to the four-parameter logistic function. The converted concentrations of the standards

340 ranged from zero to $500 \mathrm{ng} \mathrm{mL}^{-1}$. The actual hazelnut protein concentration of a dilution series of the reference sample was underestimated on average by $45 \%$ (Figure 4C). Overall,

342 small fluctuations in detection were observed upon heating the samples at $70^{\circ} \mathrm{C}$ up to $48 \mathrm{~h}$ in the absence of glucose as compared with the reference sample. Addition of soluble wheat

344 proteins $(0.25 \%$ hazelnut $+0.75 \%$ soluble wheat proteins $)$ resulted in increased detection, leading to an overestimation by an average of $34 \%$ for the samples considered. It should be

346 noted that the overestimation occurred especially in the more diluted sample solutions. In addition, due to the overestimation in the presence of soluble wheat proteins, some samples

348 were out of range (800 and $400 \mathrm{ng} \mathrm{mL}^{-1}$ ). When a lower amount of wheat proteins was added $(0.5 \%$ hazelnut $+0.5 \%$ wheat proteins $)$ the considered samples were now underestimated by

$35024 \%$ on average (data not shown). Upon heating the samples containing hazelnut and soluble wheat proteins alone, the measured hazelnut protein concentration decreased by $45 \%$ on average. Upon addition of glucose to the reference sample during heating, the discrepancy between the actual and measured hazelnut protein concentration increased further $(44 \%$ loss

354 in signal compared to the sample heated in the absence of glucose), which was even more pronounced in the presence of soluble wheat proteins (63\% loss in signal). 


\section{Biokits Hazelnut Assay}

After conversion according to formula 3.1 and 3.2, the standards of the "Biokits Hazelnut 358 Assay" covered a range from zero up to $192 \mathrm{ng} \mathrm{mL}^{-1}$ hazelnut protein and the corresponding absorbencies were fitted according to the four-parameter-logistic function. The actual 360 concentrations of the considered dilutions of the reference sample were on average overestimated by $27 \%$ (Figure 4D). Upon heating the reference sample for $24 \mathrm{~h}$ at $70^{\circ} \mathrm{C}$ 362 without glucose, the measured concentration of the samples decreased by $7 \%$ (data not shown) with an additional loss in signal of $20 \%$ when the heating was extended to $48 \mathrm{~h}$. When 364 adding soluble wheat proteins $(0.75 \%)$ to the reference sample $(0.25 \%$ hazelnut proteins $)$ the actual concentration was overestimated by about $50 \%$ on average, especially at the lower 366 concentration range, while this overestimation became only $20 \%$ when a lower amount of wheat proteins $(0.5 \%$ hazelnut and $0.5 \%$ wheat proteins) was added (not shown). Upon 368 heating in the absence of glucose the overestimation became an underestimation (14\% on average) When glucose was included during the heat-treatment of the samples, the 370 discrepancy between the actual and the measured hazelnut protein concentrations further increased, both in the presence and the absence of wheat proteins. This observation was also

372 more pronounced in the presence of soluble wheat proteins ( $48 \%$ loss in signal compared to the sample heat in the absence of glucose). 


\section{Discussion}

A comparison of the kits manuals revealed interesting differences that affected the 376 interpretation of the analytical results. Some of the kits express the results as amount of hazelnut present, while others express the results as amount of hazelnut protein present. Given

378 that the allergen in question is hazelnut proteins and since the protein content of hazelnut shows some variability, it seems more appropriate to express the results as the content of 380 hazelnut protein. Another difference observed between Ridascreen Fast Hazelnut and the other kits concerned the fitting of the calibration curve to a particular equation. The latter kit 382 suggested using the cubic spline function. However, the equilibrium reactions involved in a immunoassay make it more appropriate to use the four logistic function, or its linearized log384 logit equivalent. Moreover, the use of the alternative cubic spline function does not allow quantification of signals between zero and the first point of the calibration curve.

Use of the reference extract (obtained from a mixture of various raw and one roasted hazelnut lots) in the various kits yielded remarkable differences in their performance. The

388 Ridascreen Fast Hazelnut kit and the Biokits Hazelnut assay proved to be the most accurate, while the Veratox for Hazelnut kit showed results that underestimated by one order of 390 magnitude the actual hazelnut protein present in the reference extract. Interestingly, the accuracy of some kits depended somewhat upon the actual hazelnut protein concentration

392 present in the solutions applied. Two possible causes for the differences observed between the actual hazelnut protein concentration present in the applied reference solutions and the 394 concentration obtained by the respective kits could be suggested. One, the antibodies used in the respective kits could have been raised towards pooled hazelnut proteins extracted from

396 different hazelnut varieties than those used for our reference extract. Two, the ratio's of the different varieties in our reference mixture could also have differed. Indeed, De Meulenaer et 398 al. (2005) observed a difference in the response of antibodies raised towards the protein 
extracted from Runner peanuts and those extracted from various other peanut varieties. The 400 kits' manufacturers could also have used a protein extract from roasted hazelnuts instead. Our reference protein extract was based upon a mixture of 9 different hazelnut samples, of which 402 only one was roasted. Indeed, as can be observed from various evaluated chemical parameters linked to the Maillard reaction, it was obvious that our reference extract did not contain 404 severely modified proteins.

Heating the reference hazelnut protein solution in the absence of glucose, which 406 restricted the Maillard reaction as confirmed from the Maillard reaction parameters monitored (Figures 1 - 4), further decreased the accuracy for the Veratox for Hazelnut kit and the 408 Biokits Hazelnut assay. In the case of the former assay, the loss in accuracy became quite dramatic, with less than $10 \%$ of the hazelnut protein present being detected. Some of the 410 hazelnut proteins seem to be heat labile and denature upon incubation at $70^{\circ} \mathrm{C}$. Because of this, the kits were able to detect less as compared with the native proteins. For the other kits 412 evaluated only minor losses in accuracy could be noted, or in the case of the Hazelnut Residue kit, even a slightly increased accuracy.

414 Upon heating the reference protein solution in the presence of glucose typical chemical indicators used to assess the impact of the reaction showed a progressive increase as a 416 function of incubation time (Figure 1 and 2). These changes also clearly indicated that severe modifications on the molecular level of the hazelnut proteins occurred. Moreover, these 418 modifications gave rise to a dramatic loss in the accuracy in three of the four kits evaluated (only the Ridascreen Fast Hazelnut assay remained accurate). For the latter assay, even a 420 better binding occurred between the antibodies and the Maillard modified proteins compared to the proteins in the non-heated reference extract, most probably indicating that the 422 antibodies used in that assay alone were developed towards modified hazelnut proteins. 
As evidenced by the gel electrophoresis experiments (Figure 3), upon heating the 424 reference hazelnut protein solution in the presence of glucose, severe protein cross-linking occurred resulting in formation of high molecular weight aggregate formation. Protein cross-

linking in the Maillard reaction typically originates because reactive nucleophilic groups such as lysine (Figure 2) react with the reactive carbonyl intermediates originating from the

428 degraded reducing sugars. Since these reactive groups are present in several proteins, multiple proteins are linked to each other resulting in the formation of large molecular complexes. It is

430 thus important to note that allergen quantification is typically performed in foods in which the considered allergen is present as a minor compound next to major ingredients, including bulk

432 proteins. As a consequence, the traces of hazelnut proteins will primarily cross-link with these bulk proteins instead of cross-linking with the traces of other hazelnut proteins present.

434 Therefore, the hazelnut proteins surface may become covered with bulk proteins, making the receptor-based detection using antibodies even more vulnerable to inaccuracy. In order to

436 evaluate this hypothesis, mixtures of the reference protein with soluble wheat proteins were heated in the presence of glucose. Soluble wheat proteins were taken as a case example in 438 order to avoid solubility problems of the modified proteins as a result of progressive Maillard reaction. Since the soluble wheat protein consisted of a partially hydrolyzed mixture of wheat 440 proteins, considerably less protein aggregation occurred. This can be explained by the lower chance of retrieving multiple reactive nucleophillic groups in smaller protein fragments than

442 in intact proteins. Nevertheless, cross-linking between hazelnut proteins and soluble wheat proteins did occur. Cross-linking proved to have dramatic consequences on the accuracy of all 444 kits evaluated, which could be easily explained by the molecular modification induced on proteins and consecutively on the receptor-based principle of immune assays.

446 In view of the results obtained, it is obvious that extreme care should be taken by using receptor-based assays, such as ELISA kits for allergen detection. None of the evaluated 
448 ELISA kits produced accurate analytical results, even when non - treated reference protein solution was used. Even if the observed underestimation with the reference proteins solution 450 used in our study is due to the use of a hazelnut pool which is not similar to the ones used to raise antibodies in these kits, it should be noted that these kits are used worldwide to asses 452 contamination levels of hazelnuts of different origins, and modified to different degrees. As a consequence, care should be taken when using these kits for quantitative analysis, especially 454 in view of enforcement of for instance EC Directive 2007/68/EU. Special attention should be also drown when qualitatively interpreting the analytical data obtained. It was striking to 456 observe that the accuracy of the kits evaluated not only depended upon the chemical modifications induced in the reference protein extract, but also depended upon the actual 458 protein concentration present in the evaluated solutions. For some of the kits evaluated, a considerable lack of accuracy was observed, especially at low hazelnut protein concentrations.

460 Given that kits for allergen detection are used for trace analysis, one would expect that the concentration of the target proteins in the food extract to be low. The above results clearly 462 show that both false positive or false negative results from the commercial ELISA kits are likely to occur. False negative results present a potentially fatal risk for allergic consumers, 464 while false positive results may harm the food industry through unnecessary and costly product withdrawal. Finally, it should be realized that the final outcome of any analytical 466 method is influenced by the extractability of the analyte from the food matrix. In this perspective it is important to note that protein solubility is typically affected by progressive 468 Maillard reactions. Considering the results obtained in this study, it can be concluded that, apart from issue related to the extractability of the proteins, also chemical modifications 470 occurring on protein level as a result of the Maillard reaction may seriously affect the outcome of receptor based analytical methods, such as ELISA's. 


\section{Acknowledgements}

474 We greatly appreciate the Belgian Science Policy (SD/AF/03A) for funding this research. The authors would like to thank the Neogen Corporation for kindly providing us the Veratox 476 for Hazelnut ELISA kits for this study. 
References

480

482

484

486

488

490

492

494

496

498

500

502

504

506

508

510

512

514

AOAC Official Method 981.10. 1981. Crude Protein in Meat: Block Digestion Method. Official Methods of Analysis of AOAC, 16th edition.

Belser, M., S. Koppelman, and R. Pumphrey. 1999. Internet Symposium on Food Allergens. in .

Birmingham, N., V. Gangur, S. Samineni, L. Navuluri, and C. Kelly. 2005. Hazelnut allergy: Evidence that hazelnut can directly elicit specific IgE antibody response via activating type 2 cytokines in mice. International Archives of Allergy and Immunology 137(4):295-302.

Bjorksten, F., L. Halmepuro, M. Hannuksela, and A. Lahti. 1980. Extraction and properties of apple allergens. Allergy 35(8):671-677.

Brands, C. M. J., and M. A. J. S. van Boekel. 2001. Reactions of monosaccharides during heating of sugar-casein systems: Building of a reaction network model. Journal of Agricultural and Food Chemistry 49(10):4667-4675.

De Meulenaer, B., De la Court, D. Acke, T. De Meyere, and A. Van de Keere. 2005. Development of an enzyme-linked immunosorbent assay for peanut proteins using chicken immunoglobulins. Food and Agricultural Immunology 16(2):129-148.

deGroot, H., N. W. deJong, M. H. Vuijk, and R. G. vanWijk. 1996. Birch pollinosis and atopy caused by apple, peach, and hazelnut comparison of three extraction procedures with two apple strains. Allergy 51(10):712-718.

Englebienne, P. 2000. Data Analysis, Processing and Presentation. in Immuno and Receptor Assays in Theory and Practice.

European Parliament and Council Directive 2007/68/EC. 2007. Amending Directive 2000/12/EC as regards the indication of the ingredients present in foodstuffs. Official Journal of the European Eunion 2007 L310:11-14.

Ferrer, E., A. Alegria, R. Farre, P. Abellan, F. Romero, and G. Clemente. 2003. Evolution of available lysine and furosine contents in milk-based infant formulas throughout the shelf-life storage period. Journal of the Science of Food and Agriculture 83(5):465472.

Fields, R. 1972. The Rapid Determination of Amino Groups with TNBS. Pages 464-468 in Methods in Enzymology. Vol. 25. Hurs CHW and Tunashell S.M, ed. Academic Press, New York.

Gruber, P., W. M. Becker, and T. Hofmann. 2005. Influence of the Maillard reaction on the allergenicity of rAra $\mathrm{h} 2$, a recombinant major allergen from peanut (Arachis hypogaea), its major epitopes, and peanut agglutinin. Journal of Agricultural and Food Chemistry 53(6):2289-2296. 
Gruber, P., S. Vieths, A. Wangorsch, J. Nerkamp, and T. Hofmann. 2004. Maillard reaction and enzymatic browning affect the allergenicity of Pru av 1, the major allergen from cherry (Prunus avium). Journal of Agricultural and Food Chemistry 52(12):40024007.

Hansen, K. S., B. K. Ballmer-Weber, D. Luttkopf, P. S. Skov, B. Wuthrich, C. BindslevJensen, S. Vieths, and L. K. Poulsen. 2003. Roasted hazelnuts - allergenic activity evaluated by double-blind, placebo-controlled food challenge. Allergy 58(2):132-138.

522

524

Kiening, M., R. Niessner, E. Drs, S. Baumgartner, R. Krska, M. Bremer, V. Tomkies, P. Reece, C. Danks, U. Immer, and M. G. Weller. 2005. Sandwich immunoassays for the determination of peanut and hazelnut traces in foods. Journal of Agricultural and Food Chemistry 53(9):3321-3327.

Monaci, L., V. Tregoat, A. J. van Hengel, and E. Anklam. 2006. Milk allergens, their characteristics and their detection in food: A review. European Food Research and Technology 223(2):149-179.

Morales, F. J., C. Romero, and S. Jimenezperez. 1996. Evaluation of heat-induced changes in Spanish commercial milk: Hydroxymethylfurfural and available lysine content. International Journal of Food Science and Technology 31(5):411-418.

Nakamura, A., K. Watanabe, T. Ojima, D. H. Ahn, and H. Saeki. 2005. Effect of Maillard reaction on allergenicity of scallop tropomyosin. Journal of Agricultural and Food Chemistry 53(19):7559-7564.

Nakamura, S., Y. Suzuki, E. Ishikawa, T. Yakushi, H. Jing, and T. Miyamoto. 2008. Reduction of in vitro allergenicity of buckwheat Fag e 1 through the Maillard-type glycosylation with polysaccharides. Food Chemistry 109(3):538-545.

Pele Maria, Marcel Brohée a, Elke Anklam a, and Arjon J.Van Hengel. 2007. Peanut and hazelnut traces in cookies and chocolates: Relationship between analytical results and declaration of food allergens on product labels. Pages 1334-1344 in .

Robotham, J. M., G. G. Hoffman, S. S. Teuber, K. Beyer, H. A. Sampson, S. K. Sathe, and K. H. Roux. 2009. Linear IgE-epitope mapping and comparative structural homology modeling of hazelnut and English walnut $11 \mathrm{~S}$ globulins. Molecular Immunology 46(15):2975-2984.

Scaravelli, E., M. Brohee, R. Marchelli, and A. J. van Hengel. 2009. The effect of heat treatment on the detection of peanut allergens as determined by ELISA and real-time PCR. Analytical and Bioanalytical Chemistry 395(1):127-137.

548 Stadtman, E. R., and R. L. Levine. 2003. Free radical-mediated oxidation of free amino acids and amino acid residues in proteins. Amino Acids 25(3-4):207-218.

550 Yeung, J. M., and P. G. Collins. 1996. Enzyme immunoassay for determination of peanut proteins in food products. Journal of Aoac International 79(6):1411-1416. 


\section{Figure captions}

554 Figure 1 Formation of protein carbonyls in hazelnut protein in the presence or absence of soluble wheat proteins due to incubation with $6 \%$ glucose. The data points represent mean 556 values \pm SD of four independent determinations. $\diamond 1 \%$ hazelnut proteins with $6 \%$ glucose; $\square$ $0.5 \%$ hazelnut with $0.5 \%$ soluble wheat proteins and $6 \%$ glucose; $\Delta 0.25 \%$ hazelnut and $558 \quad 0.75 \%$ soluble wheat proteins and $6 \%$ glucose; $\circ 1 \%$ hazelnut proteins

Figure 2 Loss of reactive lysine due to incubation of hazelnut proteins in the presence or in 560 the absence of soluble wheat proteins with $6 \%$ glucose, data points represent mean values \pm SD of four independent determinations. $\diamond 1 \%$ hazelnut proteins with $6 \%$ glucose; $\square 0.5 \%$ 562 hazelnut with $0.5 \%$ soluble wheat proteins and $6 \%$ glucose; $\Delta 0.25 \%$ hazelnut and $0.75 \%$ soluble wheat proteins and $6 \%$ glucose; $\bigcirc 1 \%$ hazelnut proteins

564 Figure 3 SDS-PAGE pattern of the hazelnut proteins incubated in the presence or absence of wheat proteins with glucose: $1 \%$ hazelnut proteins and $6 \%$ glucose non treated (lane 1), 566 incubated for $24 \mathrm{~h}$ (lane 2) and $48 \mathrm{~h}$ (lane 3). 0,5\% hazelnut proteins with 0,5\% wheat proteins and 6\% glucose non treated (lane 4), incubated for $24 \mathrm{~h}$ (lane 5) and for $48 \mathrm{~h}$ (lane 6).

$5680,25 \%$ hazelnut proteins with $0,75 \%$ wheat proteins and $6 \%$ glucose non treated (lane 7 ), incubated for $24 \mathrm{~h}$ (lane 8) and $48 \mathrm{~h}$ (lane 9). Molecular weight marker (lane 10)

570 Figure 4 Ratio of measured over actual hazelnut protein concentration (Y-axis) in different ELISA kits after in duplo analysis of a dilution series (X-axis) of a reference hazelnut protein

572 sample (darkest) and after heating in the presence or absence of glucose and in the absence (left concentration on $\mathrm{X}$-axis) or presence (right concentration on $\mathrm{X}$-axis) of soluble wheat 574 proteins. $(*=$ absorbance value of sample outside the range of the standard curve)

- - reference sample, $\square$ - reference heated for $48 \mathrm{~h}, \square$ - reference heated for $48 \mathrm{~h}$ in the 576 presence of glucose, $\square-0.25 \%$ hazelnut proteins and $0.75 \%$ soluble wheat proteins, 


\begin{abstract}
$0.25 \%$ hazelnut proteins and $0.75 \%$ soluble wheat proteins heated for $48 \mathrm{~h}, \square-0.25 \%$
578 hazelnut proteins and $0.75 \%$ soluble wheat proteins heated for $48 \mathrm{~h}$ in the presence of glucose
\end{abstract}


Figure 1 Formation of protein carbonyls in hazelnut protein in the presence or absence of soluble wheat proteins due to incubation with $6 \%$ glucose. The data points represent mean values \pm SD of four independent determinations. $\diamond 1 \%$ hazelnut proteins with $6 \%$ glucose; $\square 0.5 \%$ hazelnut with $0.5 \%$ soluble wheat proteins and $6 \%$ glucose; $\Delta 0.25 \%$ hazelnut and $0.75 \%$ soluble wheat proteins and $6 \%$ glucose; $\circ 1 \%$ hazelnut proteins 
Figure 2 Loss of reactive lysine due to incubation of hazelnut proteins in the presence or in the absence of soluble wheat proteins with $6 \%$ glucose, data points represent mean values \pm SD of four independent determinations. $\diamond 1 \%$ hazelnut proteins with $6 \%$ glucose; $\square 0.5 \%$ hazelnut with $0.5 \%$ soluble wheat proteins and $6 \%$ glucose; $\Delta 0.25 \%$ hazelnut and $0.75 \%$ soluble wheat proteins and $6 \%$ glucose; $\circ 1 \%$ hazelnut proteins 


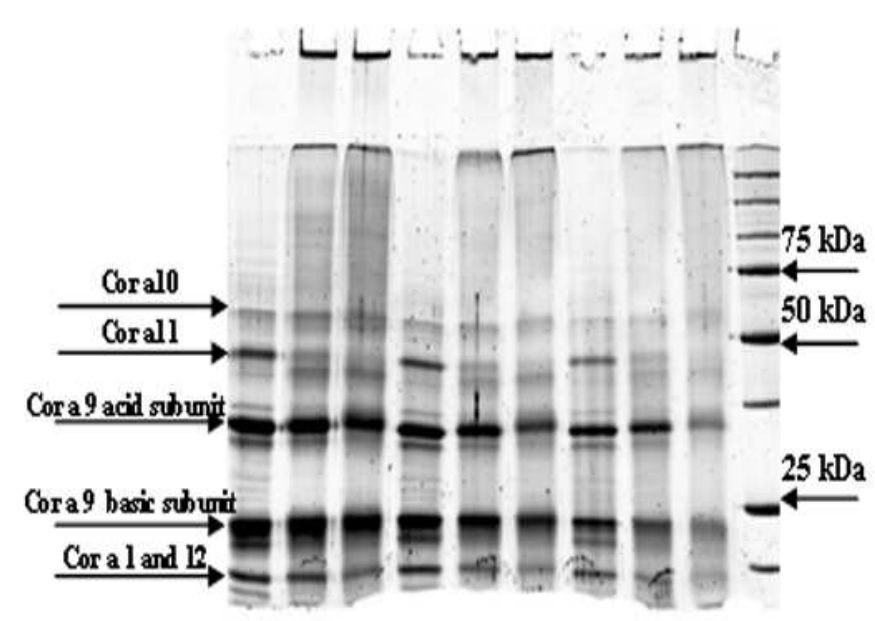

Figure 3 SDS-PAGE pattern of the hazelnut proteins incubated in the presence or absence of wheat proteins with glucose: $1 \%$ hazelnut proteins and $6 \%$ glucose non treated (lane 1), incubated for 24 $\mathrm{h}$ (lane 2 ) and $48 \mathrm{~h}$ (lane 3). 0,5\% hazelnut proteins with $0,5 \%$ wheat proteins and $6 \%$ glucose non treated (lane 4), incubated for $24 \mathrm{~h}$ (lane 5 ) and for $48 \mathrm{~h}$ (lane 6). 0,25\% hazelnut proteins with $0,75 \%$ wheat proteins and $6 \%$ glucose non treated (lane 7 ), incubated for $24 \mathrm{~h}$ (lane 8 ) and $48 \mathrm{~h}$ (lane 9). Molecular weight marker (lane 10) 
Figure 4 Ratio of measured over actual hazelnut protein concentration (Y-axis) in different ELISA kits after in duplo analysis of a dilution series (X-axis) of a reference hazelnut protein sample

(darkest) and after heating in the presence or absence of glucose and in the absence (left concentration on X-axis) or presence (right concentration on X-axis) of soluble wheat proteins. (* $=$ absorbance value of sample outside the range of the standard curve)

- reference sample, - reference heated for $48 \mathrm{~h}$, - reference heated for $48 \mathrm{~h}$ in the presence of glucose, $\quad-0.25 \%$ hazelnut proteins and $0.75 \%$ soluble wheat proteins, $-0.25 \%$ hazelnut proteins and $0.75 \%$ soluble wheat proteins heated for $48 \mathrm{~h},-0.25 \%$ hazelnut proteins and $0.75 \%$ soluble wheat proteins heated for $48 \mathrm{~h}$ in the presence of glucose 


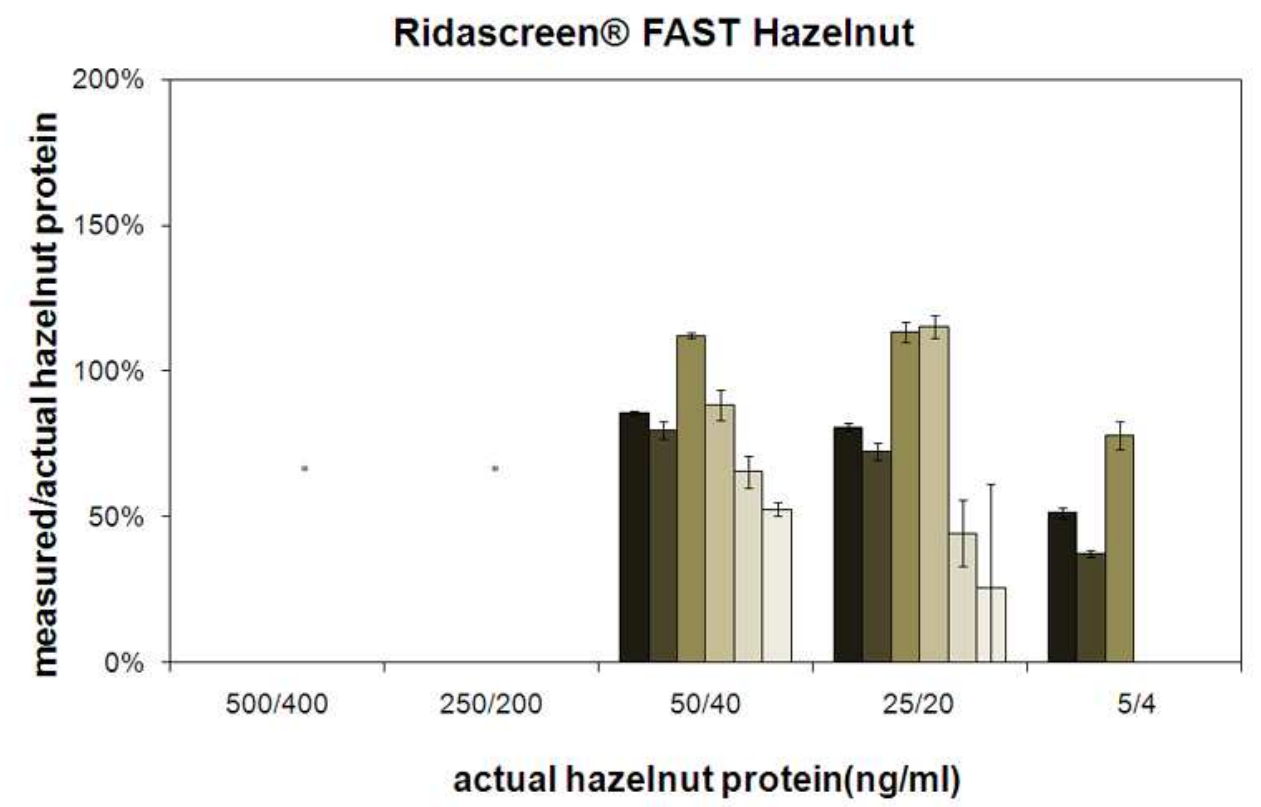

Figure 4 Ratio of measured over actual hazelnut protein concentration (Y-axis) in different ELISA kits after in duplo analysis of a dilution series (X-axis) of a reference hazelnut protein sample

(darkest) and after heating in the presence or absence of glucose and in the absence (left concentration on X-axis) or presence (right concentration on X-axis) of soluble wheat proteins. (* $=$ absorbance value of sample outside the range of the standard curve)

- reference sample, - reference heated for $48 \mathrm{~h}$, - reference heated for $48 \mathrm{~h}$ in the presence of glucose, $-0.25 \%$ hazelnut proteins and $0.75 \%$ soluble wheat proteins, $-0.25 \%$ hazelnut proteins and $0.75 \%$ soluble wheat proteins heated for $48 \mathrm{~h},-0.25 \%$ hazelnut proteins and $0.75 \%$ soluble wheat proteins heated for $48 \mathrm{~h}$ in the presence of glucose 
Figure 4 Ratio of measured over actual hazelnut protein concentration (Y-axis) in different ELISA kits after in duplo analysis of a dilution series (X-axis) of a reference hazelnut protein sample

(darkest) and after heating in the presence or absence of glucose and in the absence (left concentration on X-axis) or presence (right concentration on X-axis) of soluble wheat proteins. (* $=$ absorbance value of sample outside the range of the standard curve)

- reference sample, - reference heated for $48 \mathrm{~h}$, - reference heated for $48 \mathrm{~h}$ in the presence of glucose, $-0.25 \%$ hazelnut proteins and $0.75 \%$ soluble wheat proteins, $-0.25 \%$ hazelnut proteins and $0.75 \%$ soluble wheat proteins heated for $48 \mathrm{~h},-0.25 \%$ hazelnut proteins and $0.75 \%$ soluble wheat proteins heated for $48 \mathrm{~h}$ in the presence of glucose 
Figure 4 Ratio of measured over actual hazelnut protein concentration (Y-axis) in different ELISA kits after in duplo analysis of a dilution series (X-axis) of a reference hazelnut protein sample

(darkest) and after heating in the presence or absence of glucose and in the absence (left concentration on X-axis) or presence (right concentration on X-axis) of soluble wheat proteins. $(*=$ absorbance value of sample outside the range of the standard curve)

- reference sample, - reference heated for $48 \mathrm{~h}$, - reference heated for $48 \mathrm{~h}$ in the presence of glucose, $-0.25 \%$ hazelnut proteins and $0.75 \%$ soluble wheat proteins, $-0.25 \%$ hazelnut proteins and $0.75 \%$ soluble wheat proteins heated for $48 \mathrm{~h}$, $-0.25 \%$ hazelnut proteins and $0.75 \%$ soluble wheat proteins heated for $48 \mathrm{~h}$ in the presence of glucose 